\title{
Initial Stages in the Development of a Coupled Hillslope Hydrology- Floodplain Inundation Model
}

\author{
R. A. Charlton \\ Department of Geography, National University of Ireland, Maynooth, Co. Kildare, Ireland
}

Received 15 January 1998; accepted 6 July 1998

\begin{abstract}
Two-dimensional hydrodynamic floodplain inundation models were originally developed for civil engineering applications and have been developed to a high level of sophistication. These two-dimensional (depth averaged) schemes are capable of a high degree of spatial representation and recent developments such as their application to longer reach lengths have enabled their application in other fields including hydrology, geomorphology and ecology. These models provide a powerful tool for investigations in these fields and may be considered as a platform for further developments which incorporate specific processes occurring within the floodplain environment. It is for the case of hydrological applications that a problem has been identified in that these models do not currently consider catchment hydrology; whilst the models provide a good representation of floodplain processes in a hydraulic context, catchment hydrology is essentially treated as a black box. The only input to the system is the upstream input hydrograph (occasionally rainfall over the floodplain surface or tributary inflows are included) and output only occurs at the downstream boundary. The floodplain is assumed to be impermeable and any input from the hillslopes bordering the reach is ignored. This study discusses the initial stages of an investigation carried out to examine the signiffcance of contributions to the floodplain from the hillslopes bordering the reach. In order to do this, the zero flux boundary condition at the hillslope-floodplain interface is relaxed. A two-dimensional floodplain inundation model, RMA-2, is set up for a $14 \mathrm{~km}$ reach of the River Culm in Devon. A distributed hillslope hydrology model, VSAS3 is set up for a section of the hillslopes bordering the reach. The topography of the hillslope section is used as a geometric template, although a semitheoretical approach is adopted whereby it is assumed that the hillslope hydrological characteristics are homogenous and VSAS3 is parameterised using values reported in the literature from fleld observations. VSAS3 is coupled to RMA-2 using a simple external
\end{abstract}

Correspondence to: R. A. Charlton coupling mechanism where the hillslope discharge predicted by VSAS3 is applied to elements along the edge of the RMA-2 finite element mesh. Three storm events, with different return periods are simulated using this coupled scheme. It has been shown that hillslope inflows can have a significant effect on the predictions made by RMA-2. In addition, the timing of the hillslope inflow peak relative to the arrival of the floodwave from upstream is of great importance. (C) 1998 Elsevier Science Ltd. All rights reserved.

\section{Introduction}

In recent years there has been a growing interest in the channel-floodplain environment. This has come from a number of fields and has led to an increasing demand for information on inundation extents, depths and flow field behaviour. A number of numerical modelling schemes have been developed to solve the equations of unsteady fluid flow in their one, two and three dimensional forms. These three dimensions comprise the two horizontal ( $\mathrm{x}$ and $y)$ and vertical ( $\mathrm{z}$ ) dimensions. Two-dimensional models, which are considered here, provide a two-dimensional spatially distributed representation of the $x$ and $y$ dimensions of the channel-floodplain system while the representation of the $\mathrm{z}$ dimension is integrated with depth at each point over the floodplain surface. Although onedimensional models are widely used for a number of different applications, two-dimensional (depth averaged) models were only applied to certain classes of problem until recently. The continued development of twodimensional models means that they can now provide a viable alternative to one-dimensional schemes (Hervouet and Janin, 1994) and a number of two-dimensional codes are now available for river channel-floodplain problems (Akanbi and Katapodes, 1988; Hervouet, 1993). Recent work has led to development of these models for application to longer reach lengths, in the order of 10-20 km compared with 1-2 km (Gee et al., 1990; Bates et al., 1992). This has increased the range of two-dimensional model applications to new areas such as hydrology and sediment transport (Bates, 1992; Hervouet and Van Haren, 1996; Price, 1997). 
The use of two-dimensional models for this new type of application has thrown light on several important issues. A major problem is that the catchment hydrology is treated as a black box. Generally, the only input to the system is the upstream hydrograph and the only output the predicted downstream hydrograph. Processes such as infiltration, contributions from hillslopes bordering the reach and stream-aquifer interactions are not currently included within the structure of two-dimensional schemes. This is because these models were originally developed for engineering applications considering short reaches of less than $1-2 \mathrm{~km}$. If a longer reach is considered or if the reach is relatively far upstream, the hillslope contribution, which is the subject of this paper, could potentially be very significant. At present, any volumetric discrepancy resulting from the omission of the hillslope contribution to the floodplain-channel system would be removed during the process of model calibration which would effectively alter the volume of water stored on the floodplain.

The first pass investigation described here aims to determine if an additional input from hillslopes bordering a floodplain reach have any effect on the predictions of a two-dimensional floodplain inundation model.

\section{Research Design}

The floodplain inundation model selected was the 2dimensional model RMA-2. This was originally developed for the US Army Corps of Engineers (King and Norton, 1978). It is a finite element model with the floodplain and channel surface represented by triangular and quadrilateral elements bounded by three or four nodes. The model uses the Galerkin method of weighted residuals to solve the governing equations (the phenomologic motion equations, the continuity equation and the convection-diffusion equation) and provides spatially distributed values of velocity and depth at each time step. RMA-2 solves the depth integrated Reynolds equations for two-dimensional free surface flow in the horizontal plane using the finite element technique. Two attributes of the model make it particularly suitable for this application. Firstly, RMA-2 has successfully heen applied to longer reach lengths in the order of 10-20km (Gee et al., 1990). The model also has an in-built mechanism which allows for the relaxation of the zero-flux boundary condition along the edges of the finite element mesh. This feature was developed to allow for rainfall over the surface of an element and to simulate tributary inflows although it has not previously been used for inflows from hillslopes bordering the reach (King, pers. comm.). RMA-2 had previously been applied to an $11 \mathrm{~km}$ reach of the River Culm in Devon, UK (Fig. 1). This is a tributary of the River Exe which joins the main river $3 \mathrm{~km}$ north of Excter. The reach has a history of flooding, with floodplain inundation occurring approximately seven times a year on average. Gauging stations are sited at Woodmill (upstream) and Rewe (downstream). The set up, calibration and validation of RMA-2 for this reach is described by Bates et al. (1992). The model reach has subsequently been extended a further $3 \mathrm{~km}$ downstream. The extended $14 \mathrm{~km}$ finite element mesh for the Culm reach is shown in Fig. 2.

In providing hillslope inflow data, a modelling approach was adopted. This offered greater flexibility in exploring different scenarios than would have been possible using field measurements. It was decided to set up the hillslope hydrology model for a short $1.4 \mathrm{~km}$ wide section of the hillslope bordering the floodplain. A semi-theoretical approach was adopted, using the topography of the Culm hillslope as a geometric template and altering various hillslope parameters in order to carry out a sensitivity analysis of RMA-2 to inflows from different hillslope environments. The hillslope section was located at the upstream end of the reach.

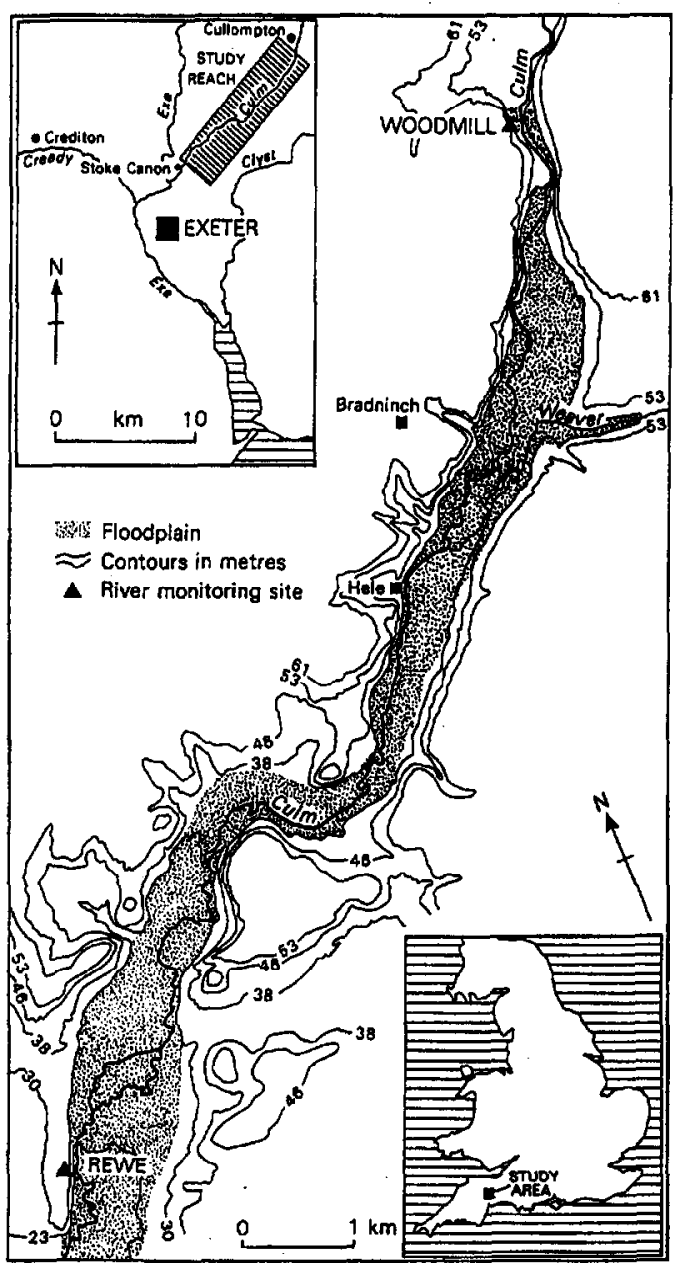

Fig. 1., Location map for the River Culm study reach 


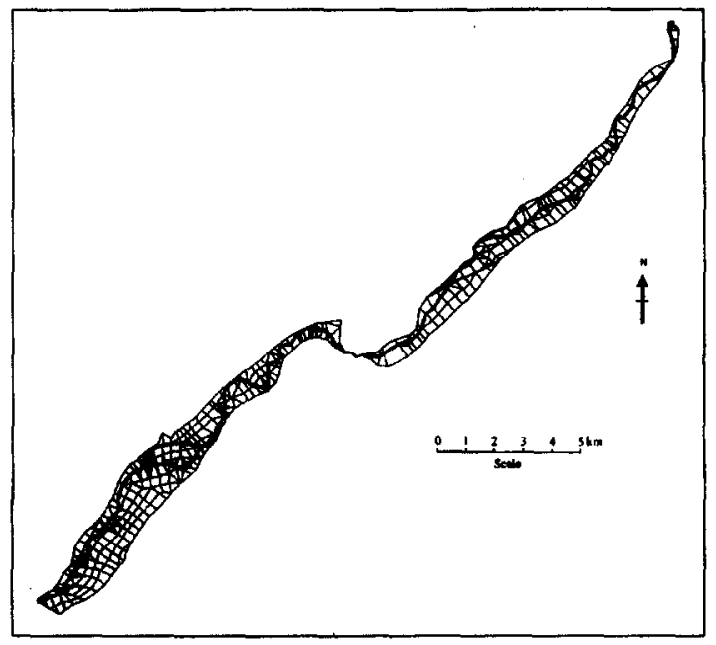

Fig. 2., The finite element mesh constructed for the Culm reach.

The hillslope hydrology model selected was the quasithree-dimensional physically based model VSAS3 (Variable Source Area Simulator). VSAS was originally devised by Troendle (1979) with new versions developed by Bernier (1982, 1985) and Whitelaw (1988). The fundamental concept which underlies the structure of this model, the variable source area concept, was originally described by Hewlett and co-workers (Hewlett, 1961; Hewlett and Hibbert, 1967). This concept describes the importance of runoff producing areas close to the stream channel which respond rapidly to precipitation. In these areas, the water table is close to the surface, rising to the surface after the onset of precipitation. Any water then falling on this saturated area is rapidly transported to the stream channel with the saturated area acting as an extension to the channel network. As a storm progresses, the saturated area expands. Within the VSAS3 framework, the catchment (hillslope) is divided into a number of segments, each of which defines a section of hillslope from the watershed boundary to the channel. The edges of segments are located along no-flow boundaries. Each segment is further sub-divided slopewise and with depth beneath the soil surface. The slopewise division uses a partitioning rule which defines progressively smaller increments towards the channel, allowing for a more accurate representation of the extent of the variable source area (closer to the channel) within the catchment. The fact that it was possible to use VSAS3 to simulate the output from an isolated hillslope section made it particularly suitable for this application although it would have been possible to use one of several hillslope hydrology models available. The downslope boundary of segments was located at the edge of the RMA-2 finite element mesh which defined the edge of the floodplain. In parameterising VSAS3 a simplistic approach was adopted because no measured flows were available from the base of the hillslope for calibration and validation of the model. Although the topography of the Culm hillslope was used as a geometric template, the semi-theoretical approach adopted assumed that the hydrological characteristics of the hillslope were homogenous. The soil water retention curve (SWRC) and saturated hydraulic conductivity were selected from standard observations typical of loam soils. The saturated hydraulic conductivity of $5.56 \times 10^{-6} \mathrm{~m} \mathrm{~s}^{-1}$ was estimated from the Brakenseik and Rawls (1983) soil property chart and the suction-moisture curve taken from Hall et al. (1977). A grassland cover and soil depth of $0.5 \mathrm{~m}$ were used. These values were in the middle of the range used for the sensitivity analysis which was later carried out.

For this first pass investigation, a simple coupling mechanism was used. This is shown schematically in Fig. 3. At each hourly VSAS3 time step, the output from the seven segments defining the hillslope was spatially averaged by dividing the volume produced by the width of the hillslope section. The spatially averaged outflow was then applied to all elements along the edge of the RMA-2 mesh. As previously stated, the zero flux boundary condition at the edge of the RMA-2 finite element mesh was relaxed using the side inflow capability. The RMA-2 input files were altered to include the volume applied to each element, weighted by the length of each element defining the edge of the mesh and divided by the area of each element.

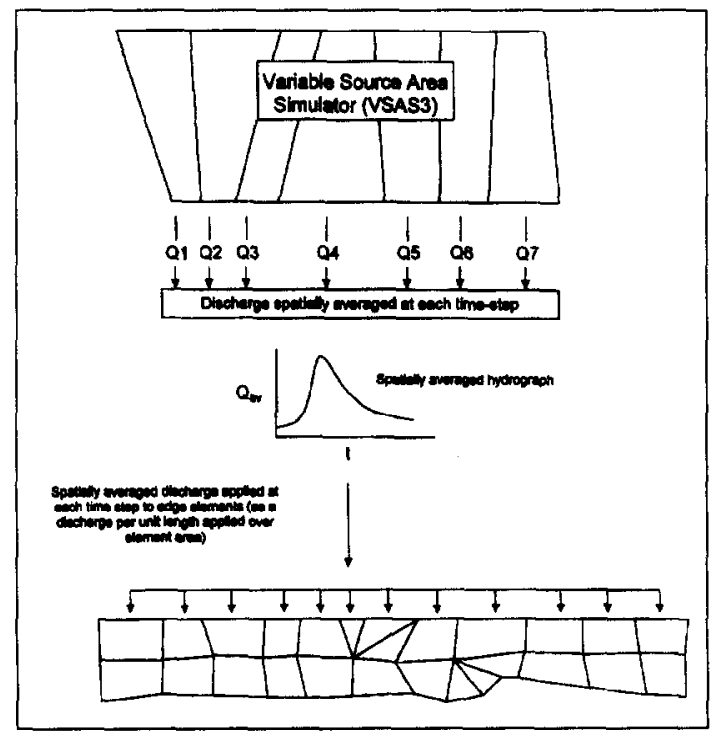

Fig.3., Diagrammatic representation of the simple coupling mechanism used.

Prior to applying these hillslope inflows, three storm events were selected with different return periods ( 1 in 1,1 
in 5 and 1 in 12) and "control" RMA-2 simulations (no inflows) were carried out in order to compare the results with simulations to which hillslope inflows were applied. These predicted downstream hydrographs were used for comparison with the results of coupled simulations in preference to the observed hydrographs because RMA-2 had originally been calibrated with the assumption that no volumetric contribution was made by the hillslopes bordering the reach.

The rainfall data for these three events was obtained from the South Western Region of the UK National Rivers Authority and was used as an input to VSAS3 in order to generate inflows which were then applied to RMA-2. Each VSAS3 simulation was started 24 hours before the start of the RMA-2 simulation although only inflows generated during the time of the coupled simulation were actually used as an input to RMA-2.

\section{Results}

The hydrographs for two of the three event return periods are shown in Fig. 4 (1 in 1 year) and Fig. 5 (1 in 12 year).

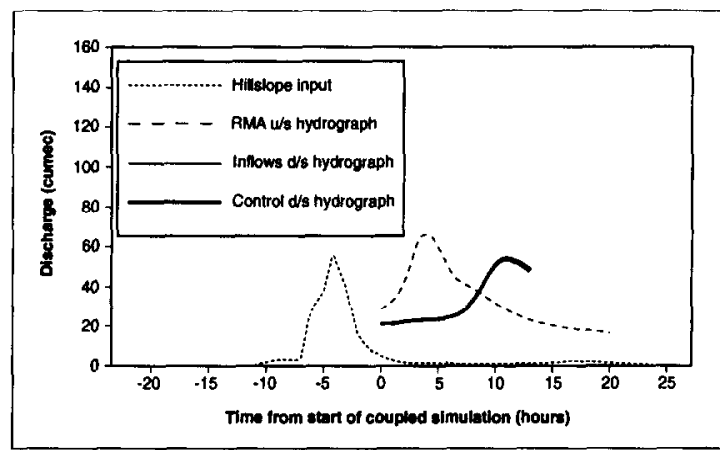

Fig. 4., Input and output hydrographs for the 1 in 1 year event.

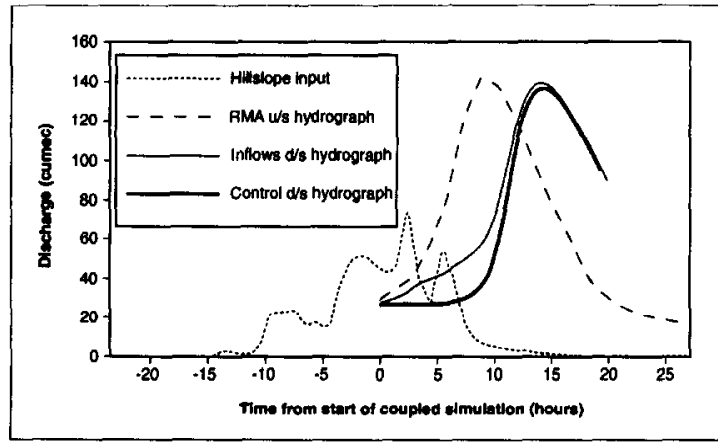

Fig. 5., Input and output hydrographs for the 1 in 12 year event.

Each of these figures show the hillslope and reach input hydrographs together with the predicted hydrographs for the control (no inflows) and coupled (with inflows) simulations. From Fig. 4 it can be seen that the 1 in 1 year storm was a single peaked event and that the main hillslope peak predicted by VSAS3 occurred before the start of the coupled simulation. This meant that the sensitivity of RMA-2 to the recession limb of the hillslope hydrograph was examined for this event. The inflows for the 1 in 1 year event appeared to have only a minor effect on the characteristics of the predicted hydrograph. Although there was no change in the timing of the hydrograph peak, a $1.07 \%$ increase in peak discharge was observed. Making a comparison between the total volume predicted at the downstream end of the reach for the control and predicted hydrographs was not entirely meaningful as the nature of the model meant that it became numerically unstable towards the end of the simulation when large numbers of dry (un-inundated) elements simultaneously left the numerical solution. For both the control and inflows simulations, the model became unstable at the same time step with a $1.42 \%$ increase in total discharge for the inflows simulation. There was a corresponding increase in the volume of water stored on the floodplain at the end of the simulation.

Fig. 5 shows that although the main hillslope peak for the 1 in 12 year event also occurred before the start of the coupled simulation, the event was multi-peaked with subsequent peaks occurring during the period of the coupled simulation. The timing of these peaks was during the rising limb of the reach input hydrograph and it is on the rising limb of the downstream predicted hydrographs that the greatest difference between control and inflows simulations is seen (Fig. 5). There was no change in the timing of the peak which showed an increase of $1.79 \%$ compared with the control. The model became unstable at the same time step for both simulations (due to a large number of elements simultaneously becoming 'dry' and leaving the numerical solution at this time step) and a volumetric increase of $16 \%$ was observed.

\section{Conclusions}

The results from this preliminary investigation indicate that the addition of hillslopes bordering a floodplain reach can produce a noticeable effect on the predictions made by two-dimensional floodplain inundation models applied to reaches longer than $10 \mathrm{~km}$. The results also illustrate the importance of the relative timing and magnitude of the hillslope and floodplain hydrograph peaks. This will be affected by a number of factors including the length of the reach under consideration, the area of the catchment upstream from the reach relative to the area of the hillslopes bordering the floodplain, the hydrological characteristics of the hillslopes and the processes by which water is actually delivered to the floodplain.

In coupling the models, a relatively crude method has been used to effect a one-way transfer of water from the 
hillslopes to the floodplain. Although this coupling mechanism might provide adequate representation of the situation where a narrow floodplain is adjoined by hillslopes dominated by shallow subsurface and surface flow, for systems with a significant groundwater component it is cleárly inappropriate. This is because the transfer of water from the hillslopes to the floodplain would not only occur at the hillslope tloodplain boundary (as assumed here) but across the surface-subsurface interface of the whole floodplain-channel system. In addition, this transfer between surface and groundwater can occur in both directions. The coupling mechanism adopted to represent the transfer of water is very likely to have a major influence on the relative timing of hillslope and floodplain peaks. For the simulations carried out here, the main hillslope inflows hydrograph peak occurred before the onset of the coupled simulation. This was hecause, due to the size of the catchment, there is a lag time of approximately 24 hours between peak rainfall and the hydrograph peak observed at the upstream end of the reach. This travel time obviously does not apply to the hillslopes bordering the reach. All the water predicted at the base of the hillslope was applied to the floodplain with no time lag to allow for the processes of water transfer from the hillslopes to the floodplain. In reality such a rapid delivery of water to the floodplain is unlikely. Were a more physically representative coupling mechanism implemented, it is possible that the hillslope contribution to the floodplain would be attenuated so that it occurred during or even after the period of the floodplain model simulation. The hydrological interaction which occurs between the floodplain and bordering hillslopes involves many complex and inter-related processes and in order to justify designing and implementing a more physically representative coupling scheme, it was thought necessary first to determine the sensitivity of the floodplain model to hillslope inflows and to assess the effect of this additional input on the calibration of the model.

The work following on from that discussed here involved carrying out a sensitivity analysis to examine the sensitivity of RMA-2 to inflows from hillslopes with different hydrological parameters (soil depth, hydraulic conductivity, antecedent conditions, slope angle) and examining changes in patterns of inundation and depth over the floodplain surface in addition to changes in the characteristics of the downstream hydrograph. The effect of this additional input on the calibration of RMA-2 has also been investigated and will be reported in a later paper.

\section{Acknowledgements}

This research was funded by a Natural Environment Research Council studentship and was carried out in the Geography Department at the University of Bristol under the supervision of Professor M. G. Anderson. I would like to thank Jim Keenan (Cartographer, Department of Geography, N.U.I. Maynooth) for his help in producing the figures.

\section{References}

Akanbi, A.A. and Katapodes, N.D., 1988. Model for flow propagation on initially dry land. Journal of the Hydraulics Division, ASCE, 114: 689. 706.

Bates, P.D., Anderson, M.G., Baird, L., Walling, D.E. and Simm, D., 1992. Modelling floodplain flows using a two-dimensional finite element model. Earth Surface Processes and Landforms, 17.

Bernier, P.Y., 1982. VSAS2: A revised source area simulator for small forested basins. Unpublished PhD thesis, University of Georgia, Athens, Georgia.

Bernier, P.Y., 1985. Variable source areas and stormflow generation, an update of the concept and a simulation effort. Journal of Hydrology. 79: 195-213.

Brakenseik, D.L. and Rawls, W.J 1983. Use of infiltration procedures for estimating runoff. Paper presented to Soil Conservation Workshop, Tempe, Arizona.

Gee, D.M., Anderson, M.G. and Baird, L., 1990. Large scale floodplain modelling. Earth Surface Processes and Landforms, 15: 513-523.

Hall, D.G.M., Reeve, M.J., Thomasson, A.J. and Wright, V.F. 1977. Water retention, porosity and density of field soils. Soil Survey Technical Monograph 9, Soil Survey of England and Wales, Hapenden.

Hervouet, J.M., 1993. Validating the numerical simulation of dam breaks and floods. Proceedings of the International Conference in Hydroscience and Engineering, Washington.

Hervouet, J.M. and Janin, J.M., 1994. Finite element algorithns for modelling flood propagation. In Molinaro, P. and Natale, L. (eds.), Modelling of flood propagation over initially dry areas. Proceedings of the speciality conference, co-sponsored by ASCE-CNR/GNDCI-ENEL spa: 102-113.

Hervouet, J.M. and Van Haren, L., 1996. Recent advances in Numerical methods for fluid tlows, in Floodplain Processes, M.G. Anderson, D.E. Walling and P.D. Bates (eds.), Wiley, Chichester, pp. 183-214.

Hewlett, J.D., 1961. Watershed Management, in Report for 1961 Southeastern Forest Experiment : ation, US Forest Service, Ashville, N.C.

Hewlett, J.D. and Hibbert, A.R., 1967. Factors affecting the response of small watersheds to precipitation in humid areas, in Forest Hydrology, W.E. Sopper and H.W. Lull (eds.), Pergammon, Oxford, pp. 275-90.

King, I.P. and Norton, W.R., 1978. Recent applications of RMA's finite element models for two-dimensional hydrodynamics and water quality. Proceedings of the Second International Conference on Finite Elements in Water Resources. Pentech Press, London: 81-99.

Price, D.A., 1997. An integrated approach to modelling floodplain hydraulics, hydrology and nitrate chemistry. Unpublished $\mathrm{PhD}$ thesis, University of Bristol.

Troendle, C.A., 1979. A variable source area model for storm flow prediction on first order forested catchments. Unpublished $\mathrm{PhD}$ thesis. University of Georgia.

Whitelaw, A.S., 1988. Hydrological modelling using variable source areas. Unpublished PhD thesis, University of Bristol. 